\title{
DESAFIOS DA ACIDEZ NA CATÁLISE EM ESTADO SÓLIDO
}

\author{
Esteban Lopez Moreno* \\ Diretoria de Extensão, Fundação Centro de Ciências e Educação Superior a Distância do Estado do Rio de Janeiro, Rua Visconde \\ de Niterói, 1364, 20943-001 Rio de Janeiro - RJ, Brasil
}

Krishnaswamy Rajagopal

Escola de Química, Centro de Tecnologia, Universidade Federal do Rio de Janeiro, Ilha do Fundão, 21949-900 Rio de Janeiro RJ, Brasil

Recebido em 30/5/07; aceito em 30/7/08; publicado na web em 26/1/09

\begin{abstract}
CHALLENGES OF CATALYSIS ACIDITY IN SOLIDS. This study explores the similarities between solid and liquid acid catalysts highlighting the advantages and the main challenges of heterogeneous catalytic processes. We describe the main developments in technical procedures like selection of compounds and reaction models involved in: increasing acidity, characterization of solid acidity and in coke formation.
\end{abstract}

Keywords: acidity; acidity in solids; acid catalysis.

\section{INTRODUÇÃO}

Antes de serem compreendidos como uma categoria à parte ou muito antes da própria existência humana, ácidos protônicos - tais quais ácido cianídrico, ácido fórmico e ácido acético - estavam presentes em diversos fragmentos de corpos celestes, como asteróides, ou mais comumente aprisionados no "gelo" de cometas. Segundo a hipótese conhecida como "nova panspermia", o surgimento da vida na Terra teria sido viabilizada pelo abastecimento desses ácidos, entre outras substâncias orgânicas, sobre a nossa superfície, trazidas do espaço pelos cometas. ${ }^{1,2}$

No decorrer do tempo, o ser humano notabilizou-se pela capacidade de manipulação e entendimento dos ácidos, que foi fundamental para a evolução da espécie e ainda essencial para a sua sobrevivência atual e futura. Por exemplo, o aquecimento global, resultado do efeito estufa provocado pela emissão de gases como o $\mathrm{CO}_{2}$ e $\mathrm{CH}_{4}$, é uma das questões de sobrevivência que tem preocupado seriamente a humanidade. Uma das alternativas viáveis de atenuação deste efeito é por meio de eletrocatálise do $\mathrm{CO}_{2}$, de forma a convertê-lo em combustíveis recicláveis, como $\mathrm{CH}_{3} \mathrm{OH}, \mathrm{CH}_{3}-\mathrm{O}-\mathrm{CH}_{3}$, ou em ácido fórmico, formaldeído, etileno, propileno, etc. ${ }^{3}$

O desenvolvimento de novos catalisadores, especialmente os sólidos, desde a síntese até a operacionalização final, envolve uma série de procedimentos que necessitam de profundo conhecimento de mecanismos ácido-base. O objetivo deste trabalho consistiu em investigar algumas das principais incompletudes atuais para a conceitualização da acidez na catálise no estado sólido, comparando-as com o meio líquido.

\section{ENTENDIMENTOS MODERNOS DE ACIDEZ E BASICIDADE}

Ao final do século XIX, o químico Svante Arrhenius (1859-1927) definiu ácidos e bases em termos de propriedades dissociativas de íons, porém ainda não fora esclarecido que substâncias eram formadas. A idéia da existência de íons não era nova, uma vez que Michael Faraday (1791-1867) já a tinha considerado em função de seus expe-

*e-mail: estebanlmoreno@gmail.com rimentos de eletrólise. No entanto, a proposta de Arrhenius era mais revolucionária, pois considerou que os íons poderiam ser formados na ausência de corrente elétrica e, além disso, seriam responsáveis por diversas reações químicas.

Não obstante o seu sucesso, a teoria de Arrhenius não se aplicava de forma adequada a soluções que não fossem aquosas e tampouco previra que certas substâncias poderiam provocar a liberação de $\mathrm{H}^{+}$ ou $\mathrm{OH}^{-}$sem conter estes íons em sua fórmula. A aplicação da teoria de Arrhenius também não abrangia os sólidos, mas pouco a pouco outras teorias vieram somar informações para a compreensão sobre a acidez. Arrhenius jamais aceitou os conceitos que se seguiram. ${ }^{4}$

Diversas generalizações foram desenvolvidas após as formulações iniciais de Arrhenius, dentre as quais aquelas que receberam maior reconhecimento foram os conceitos protônicos de J. Brønsted e T. Lowry e o conceito eletrônico de G. N. Lewis. Um amplo resumo histórico comparativo das principais definições de ácidos e bases e as relações históricas e conceituais que conduziram ao sucesso ou fracasso de cada proposta consta do artigo de Chagas. ${ }^{5} \mathrm{O}$ estabelecimento do conceito de $\mathrm{pH}$ e a evolução da medida de acidez está muito bem descrito na referência 6 .

Em 1923, o dinamarquês Johannes Nicolaus Brønsted (18791947) e o inglês Thomas Martin Lowry (1874-1936) propuseram, independentemente, uma nova concepção de acidez e basicidade, na qual o ácido foi definido como qualquer substância que atua como um doador do cátion hidrogênio (próton, $\mathrm{H}^{+}$), e a base como qualquer substância que recebe o próton, independente da natureza do solvente. Esta concepção "protônica" estendeu a definição anterior de Arrhenius, que era limitada a meios aquosos, além de eliminar a obrigatoriedade da presença do grupamento monovalente $\mathrm{OH}^{-}$, a hidroxila (ou oxidrila).

Uma contribuição importante de Lowry foi ter percebido que o próton não poderia ser a espécie verdadeiramente transferida. ${ }^{7} \mathrm{De}$ fato, prótons livres $\left(\mathrm{H}^{+}\right)$não existem em solução, pois uma vez dissociados imediatamente coordenam-se a outras espécies, em função do ambiente químico que o envolve, formando uma nova estrutura. No caso mais comum, em meio aquoso, Lowry representou a entidade transferida como o hidrônio (ou oxônio ou hidroxônio, $\mathrm{H}_{3} \mathrm{O}^{+}$), o que atualmente é considerado uma sobre-simplificação. Alguns autores sugerem que uma melhor representação seria $\mathrm{H}^{+}\left(\mathrm{H}_{2} \mathrm{O}\right)_{4}$ 
ou $\mathrm{H}^{+}\left(\mathrm{H}_{2} \mathrm{O}\right)_{21}$, por exemplo, em que o segundo arranjo forma um dodecaedro pentagonal. ${ }^{8}$ No entanto, devido à alta mobilidade do próton, nenhuma representação é completamente adequada. Isto porque todas as estruturas são rapidamente dissipadas e o máximo que podemos especular é uma estrutura formada de um número médio de moléculas de água (ou outro solvente) circundando um próton.

Apesar do significativo avanço com as concepções de Brønsted e Lowry, o modelo ainda era limitado, pois não considerava as reações entre ácidos e bases sem a transferência de prótons. Esta deficiência foi remediada com o trabalho do químico norte-americano Gilbert N. Lewis (1875-1946).

Na definição Lewis, ácido é qualquer substância que atua como receptor de um par de elétrons, enquanto a base opera como doador de um par de elétrons. O próton pode ser entendido como um ácido de Lewis, uma vez que este pode se ligar a um par de elétrons. Então, todo ácido segundo a definição de Brønsted-Lowry é também um gerador de ácido de Lewis. Semelhantemente, toda base de BrønstedLowry é uma base de Lewis.

No entanto, quando as reações entre espécies envolvem transferência de prótons, costuma-se aplicar somente o conceito de ácidobase de Brønsted-Lowry.

Existem, porém, diversas substâncias, outrora sem classificação quanto à acidez, que passaram a ser compreendidas como tal, segundo a visão de Lewis. A teoria eletrônica de Lewis possibilitou uma série de avanços na exploração da acidez. Uma vasta gama de reações químicas puderam, a partir de então, ser compreendidas pelo conceito de ácido e base de Lewis. As reações de oxi-redução (REDOX) por vezes também são incluídas dentro da definição de Lewis, porém, como nem sempre a mudança do número de oxidação envolve a transferência de elétrons (tal qual na formação de complexos químicos covalentes), esta apropriação conceitual é ambígua.

Seguiram-se diversos refinamentos à teoria de Lewis, como os efeitos geométricos das ligações; interações entre ligantes e não ligantes; computação quântica da acidez; ${ }^{9}$ correlação com propriedades termodinâmicas; ácidos e bases duros e macios; e "ácidos mágicos".

\section{OS DESAFIOS DA ACIDEZ NO ESTADO SÓLIDO}

A partir do século XIX ampliou-se sobremaneira a utilização dos ácidos na indústria, como na catálise de reações químicas, com participação em diversos processos essenciais, tais como craqueamento, desidratação, isomerização, alquilação e desproporcionamento. As reações catalisadas por ácidos, sejam sólidos ou líquidos, estão indubitavelmente dentre as mais importantes e as mais estudadas da química.

Durante as últimas décadas, existe uma forte tendência em tornar diversos processos industriais homogêneos em heterogêneos em função da facilidade operacional - i.e., maior intervalo de temperatura, menor esforço na separação de produtos dos catalisadores sólidos - além de maior seletividade. Os ácidos sólidos apresentam ainda grande vantagem ambiental, devido à maior possibilidade de reutilização, reciclagem ou eliminação dos catalisadores, enquanto para as reações catalisadas em meio líquido os ácidos se tornam um passivo ambiental de maior custo de tratamento.

Não obstante os extraordinários avanços quanto à compreensão da acidez no estado sólido, em relação ao montante de catalisadores utilizados industrialmente, a maioria dos processos continua a utilizar reações em meio líquido. Há certamente boas vantagens em utilizar este meio. Por exemplo, não há limitação de acessibilidade ao catalisador por moléculas grandes no meio líquido, como é usual na produção de fármacos ou no tratamento de hidrocarbonetos pesados. Além disso, uma vez que a tecnologia está comparativamente bem desenvolvida e o valor dos ácidos é geralmente baixo, o custo de implementação de um processo em fase líquida é substancialmente inferior. Por isso, freqüientemente, a opção por uma reação com catalisador ácido em fase liquida ocorre como uma solução imediata, por falta de uma alternativa tecnológica ou economicamente mais viável.

No entanto, as pesquisas em busca por ácidos sólidos com características catalíticas aceitáveis cresceram bastante nos últimos anos. As tentativas de heterogeneização têm esbarrado em uma série de dificuldades. O que veremos a seguir são alguns dos principais desafios impostos para o incremento, caracterização da acidez e diminuição da formação de coque em catalisadores sólidos, respectivamente.

\section{Incrementando a acidez}

No entendimento da acidez em sólidos, a visão protônica de Brønsted-Lowry e a eletrônica de Lewis respondem, tradicionalmente, por sistemas distintos. A acidez de Brønsted é marcante nos mecanismos envolvendo craqueamento ou hidrocraqueamento de hidrocarbonetos, dois dos processos mais importantes da indústria de refino de petróleo. O grupo doador de prótons é usualmente representado de forma simplificada como $\mathrm{um}^{+}$ligado a um átomo de oxigênio (-OH) em superfícies de óxidos, e é chamada de sítios ácidos de Brønsted ou BAS (Brønsted acid site). Nestes materiais os grupos básicos são os íons oxigenados $\left(\mathrm{O}^{-}\right)$resultantes da dissociação do próton ou gerados por desidratação de duas hidroxilas terminais $\left(\mathrm{X}-\mathrm{OH}+\mathrm{X}-\mathrm{OH} \rightarrow \mathrm{X}-\mathrm{O}^{-}+\mathrm{H}_{2} \mathrm{O}\right)$. A acidez de Lewis comumente está associada aos sistemas não próticos resultantes da interação com metais, principalmente os metais de transição através de seus orbitais $d$ incompletos, capazes de receber elétrons. Freqüentemente estes metais formam catalisadores, homogêneos ou heterogêneos, com a habilidade de processar com eficiência diversas reações químicas.

Uma das principais dificuldades da utilização de sistemas ácidos heterogêneos é que no meio sólido, usualmente, é necessário um esforço adicional para incrementar e estabilizar a acidez superficial. A superfície da sílica $\left(\mathrm{SiO}_{2}\right)$, por exemplo, praticamente não produz sítios ácidos de Lewis, pois forma com facilidade silanóis ( $\mathrm{Si}-\mathrm{OH})$ que são considerados sítios ácidos de Brønsted, e estes cobrem a superfície interna e externa do sólido. No entanto, em termos de força, a acidez dos silanóis é normalmente fraca ou no máximo moderada. ${ }^{10,11}$

A acidez de Brønsted nas sílicas também pode ser significativamente incrementada pela substituição isomórfica dos átomos de silício, que possuem carga formal +4 , por cátions trivalentes, como alumínio, gerando uma carga negativa para cada átomo substituído. Cada carga negativa residual da rede é neutralizada na superfície do sólido por outros cátions, usualmente metais alcalinos ou alcalinos terrosos, chamados de "cátions de compensação". Para substituí-los por prótons, ou seja, para que se forme um sítio ácido de Brønsted, utiliza-se usualmente um procedimento de troca iônica com uma solução aquosa de cloreto de amônio, seguido de lavagem, para a retirada de cloreto residual, e calcinação (Figura 1).

Os aluminossilicatos de elevada cristalinidade são conhecidos como zeólitas (ou zeólitos) e, normalmente, são sintetizados na forma sódica a partir da reação de sais (cátion $\mathrm{Na}^{+}$). Uma fração de cátions de sódio na estrutura final funcionará como cátions de compensação. Além da acidez de Brønsted, os aluminossilicatos também possuem acidez de Lewis, associada ao alumínio substituído isomorficamente pelo silício. Neste caso, o próprio alumínio forma sítios ácidos de Lewis na superfície da zeólita, quando submetido à desidratação (Figura 1c).

A acidez destes materiais depende essencialmente da localização 
(a)

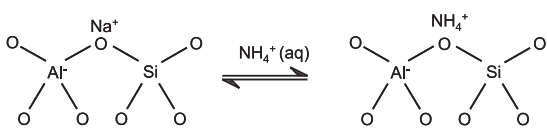

(b)

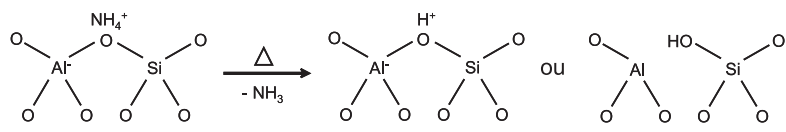

(c) 2

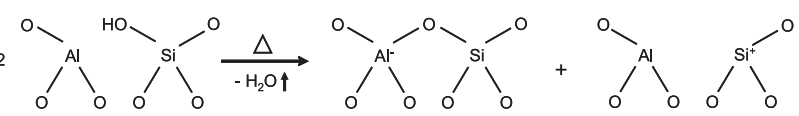

Figura 1. Etapas de troca iônica para a geração de acidez de Brønsted e desidratação para geração de acidez de Lewis: (a) troca do íon sódio pelo íon amônio; (b) decomposição do íon amônio com liberação do amoníaco e geração do sítio ácido de Brønsted; (c) desidratação de sítio ácido de Brønsted para geração de sítio ácido de Lewis

e do conteúdo de alumínio na estrutura do silicato, além do estado de coordenação do alumínio, sendo freqüentemente desejável, no caso das zeólitas, a coordenação tetraédrica $\left(\mathrm{AlO}_{4}^{-}\right)$.

A quantidade de sítios ácidos nas zeólitas está relacionada à razão $\mathrm{Si}: \mathrm{Al}$ ou $\mathrm{SiO}_{2} / \mathrm{Al}_{2} \mathrm{O}_{3}$ (ou SAR - silica/alumina ratio), ou seja, quanto menor esta relação, mais alumínio está presente na estrutura e maior a quantidade de cátions de compensação, i.e., maior o número de sítios ácidos, no caso de estar na forma protônica. No entanto, como a geração dos sítios ácidos está associada ao desbalanceamento de cargas gerado pela substituição isomórfica de ânions de cargas diferentes, quanto maior o número de átomos de alumínio, menos desbalanceada estará a rede e menor será a força dos sítios ácidos. Diminuindo-se o SAR da zeólita, a estrutura também se torna menos estável, podendo comprometer ou mesmo destruir o arranjo cristalino. ${ }^{11}$

No caso de haver baixa densidade de sítios ácidos de Brønsted, como na zeólita Y ou ZSM-5 nas formas protônicas, a força ácida é alta, pois os prótons não dissociados pouco interagem entre si. Com a finalidade de aumentar a força dos sítios ácidos e a estabilidade da estrutura, zeólitas com baixo teor de alumínio são preparadas por processos de desaluminização. Zeólitas Y que passam por este procedimento são chamadas de zeólitas Y ultra-estáveis (USY - $U l$ traStable $Y$ zeolite) e comportam vasta aplicação nos processos de craqueamento catalítico, entre outros.

As zeólitas são exemplos clássicos da capacidade de controle da quantidade (densidades) e natureza (força) de sítios ácidos, o que garante, entre outras propriedades importantes, o especial apreço por estes materiais. Porém, existem inúmeras alternativas aplicáveis para outros óxidos ou mesmo para as zeólitas. Por exemplo, a alumina é um suporte largamente utilizado em catálise, mas apresenta apenas sítios ácidos de Lewis. Todavia, depositando-se óxido de nióbio (nióbia) sobre a superfície da alumina, é possível conferir-lhe acidez de Brønsted. ${ }^{12}$ A ancoragem ou deposição superficial de compostos com propriedades ácidas, como metais, óxidos metálicos ou heteropoliácidos, é uma alternativa eficiente para se incrementar a acidez de catalisadores sólidos.

Os metais e os óxidos metálicos, suportados ou não, possuem uma vasta aplicação em inúmeros processos catalíticos. A compreensão da força ácida de Lewis envolvida nesses processos é uma etapa importante, e para estudá-la é necessário considerar a natureza química das moléculas ou espécies químicas que estão interagindo. Se o "ácido metálico" do catalisador interagir fortemente com uma base (reagente), formará um composto estável e a decomposição do reagente será uma etapa limitante para a reação. É o caso de um sistema de reação formado por ácido/base duro, ou ácido/base macio.
Por outro lado, se a interação entre o ácido e os reagentes não for suficientemente forte, a taxa de formação dos intermediários será reduzida e a reação poderá não ocorrer. Entre esses extremos estão os metais (ou as espécies químicas) que estão mais "habilitados" à atividade catalítica. Esta propriedade é conhecida na catálise como princípio de Sabatier, segundo o qual existe uma força de ligação ótima entre os reagentes/produtos e o catalisador.

Um exemplo ilustrativo de sistemas ácido-base de Lewis na catálise é o processo Haber para a obtenção da amônia $\left(\mathrm{N}_{2}+3 \mathrm{H}_{2} \rightarrow\right.$ $2 \mathrm{NH}_{3}$ ), publicado por Fritz Haber em 1905..$^{5} \mathrm{O}$ catalisador (mássico) de ferro para esta reação é obtido pela redução da magnetita ( $\mathrm{FeO}$. $\mathrm{Fe}_{2} \mathrm{O}_{3}$ ou $\left.\mathrm{Fe}_{3} \mathrm{O}_{4}\right)$ a altas temperaturas, além da adição de alguns promotores (e.g. $\mathrm{SiO}_{2}, \mathrm{MgO}$, etc). Os orbitais $d$ vazios do ferro metálico conferem-lhe acidez de Lewis; deste modo, moléculas de nitrogênio e de hidrogênio são adsorvidas na superfície do sólido. Nesta quimissorção ocorre uma transferência de carga das moléculas de $\mathrm{H}_{2}$ e $\mathrm{N}_{2}$ para o ferro metálico, que enfraquece as ligações $\mathrm{H}-\mathrm{H}$ e N-N, propiciando por meio de um rearranjo energético a formação da amônia. Para que a amônia formada na superfície do catalisador dessorva, ocorre transferência de carga agora do metal, de modo que o ferro passa a atuar também como uma base de Lewis e a amônia como seu ácido conjugado. Observe-se que não houve formação de cátions ou ânions, porém existem nos intermediários de quimissorção, uma carga formal negativa no ferro (ácido de Lewis) e uma carga positiva nas moléculas de hidrogênio e nitrogênio (bases de Lewis).

Para a incorporação e/ou a adequação das espécies ácidas de Lewis ou de Brønsted, existe uma série de estratégias de síntese que podem ser desenvolvidas, como impregnação, deposição, precipitação, calcinação, redução, etc. As variações estruturais são muito diversificadas, e inúmeras espécies químicas podem ser incorporadas à superfície de um suporte, em composição, estados de oxidações e ambientes químicos variados.

\section{A caracterização da acidez em sólidos}

Um dos principais desafios para a avaliação da acidez em sólidos resume-se na busca de uma escala simples e representativa para sua caracterização. Ou seja, enquanto no meio líquido é relativamente fácil estabelecer um padrão para a acidez, como o $\mathrm{pK}_{\mathrm{a}}$, escala de Hammett $\left(\mathrm{H}_{0}\right)$ ou atividade $\left(\mathrm{a}_{\mathrm{H}}+\right)$, no sólido, apenas a acidez de Hammett tem algum significado prático, embora restrito. Como a topologia da superfície no sólido é usualmente complexa, podendo promover vários tipos de interações ácido-base e com diferentes espécies presentes, em um catalisador sólido podem coexistir sítios ácidos de diferentes forças, seja de Brønsted ou de Lewis, e com densidades de distribuição variadas. Acrescente-se o fato que as energias de solvatação das espécies líquidas, fundamentais no processo de transporte dos intermediários ácidos ou básicos, não são as mesmas na superfície de um sólido. Por isso a estimativa da força nos meios líquidos e sólidos não é compatível, mesmo com a obtenção dos mesmos produtos. ${ }^{13}$

É incorreto, por isso, sugerir afirmações comparativas do tipo: "uma zeólita tem a mesma acidez que o ácido sulfúrico concentrado", ou "tal sólido não tem acidez suficiente para determinada reação", sem que se esclareça que estas estimativas usualmente levam em conta somente parâmetros termodinâmicos em solução.

Não há, portanto, como esperar encontrar um modelo simples que forneça um valor representativo para a caracterização e entendimento da acidez no sólido. Existem, porém, diversas técnicas que se habilitam a qualificar e quantificá-los. Estas normalmente são complementares, havendo as que são melhores para a determinação da densidade dos sítios, enquanto outras são importantes na 
caracterização da natureza do sítio ácido e, finalmente, há as que utilizam reações modelos para estimar a acidez. Isoladamente, cada um destes procedimentos permite interpretações importantes, mas ainda limitadas e algumas vezes incompatíveis com outros resultados esperados. ${ }^{14}$

Entre as técnicas de medida da densidade de sítios ácidos, as mais importantes são os métodos de dessorção térmica programada (TPD - Thermal Programmed Desorption), tipicamente de moléculas sonda básicas quimissorvidas, como a amônia ou aminas. Neste método a molécula sonda é adsorvida sobre a amostra limpa e então se procede à dessorção aumentando-se a temperatura de forma controlada. A determinação da quantidade dessorvida e, conseqüentemente, do número de sítios ácidos pode ser feita analisando-se o gás que evolui da amostra, por cromatografia a gás ou espectrometria de massas, ou determinando-se a perda de massa da amostra por análise termogravimétrica. O número total de sítios ácidos está relacionado à área total das curvas de TPD geradas pelas medidas cromatográficas, de espectrometria ou pela perda de massa, enquanto a força é proporcional à temperatura na qual ocorre a dessorção das espécies. Quanto mais forte o sítio ácido, maior a interação com o adsorvato e maior a temperatura necessária para retirá-lo (i.e., dessorvê-lo). ${ }^{13,14}$

O TPD de amônia é uma técnica relativamente barata, bem estabelecida e que permite obter resultados satisfatórios em pouco tempo. Contudo, têm-se relatado alguns contratempos, como a não especificidade da amônia para os sítios ácidos de Brønsted, o qual, sendo uma base muito forte, pode quimissorver em sítios ácidos muito fracos, dificultando a interpretação. Outro problema importante a ressaltar é que os resultados dificilmente são reprodutíveis em outros equipamentos devido à extrema sensibilidade de algumas condições operacionais, como a forma de preparação da amostra ou construção do equipamento. Apesar do TPD da amônia ser ainda razoavelmente utilizado, principalmente para sistemas relativamente bem conhecidos, o TPD da decomposição de aminas tem sido considerado uma alternativa mais eficaz e robusta em relação aos empecilhos encontrados com a amônia. ${ }^{15}$

A caracterização da natureza do sítio ácido pode ser realizada por espectroscopia de infravermelho (IV), ressonância magnética nuclear (RMN) ou por microcalorimetria, entre outras técnicas. A espectroscopia de IV é uma das técnicas mais comuns para se avaliar a natureza da acidez em sólidos porosos. Tradicionalmente utilizase a quimissorção da molécula de piridina como molécula sonda. A interação da piridina com os sítios ácidos de Brønsted ou de Lewis gera espécies com freqüências de vibração características, que são correlacionadas aos sítios. Pode ser feita a quantificação destas espécies pela área das bandas formadas nos espectros, de acordo com a lei de Lambert-Beer. O monóxido de carbono também é uma molécula sonda bastante utilizada no estudo de acidez em sólidos, mas as medidas têm de ser realizadas a baixa temperatura, pois o CO é uma base muito fraca, o que constitui uma dificuldade a mais. $\mathrm{O}$ maior problema associado a estas medidas está sempre na quantificação absoluta dos sítios ácidos ou básicos, sendo muitas vezes limitado a comparações relativas entre amostras. ${ }^{14}$

A caracterização das propriedades ácidas de catalisadores é essencial no levantamento dos padrões de atividade em reações que ocorrem via mecanismo ácido-base. Neste caso, a própria reação catalítica pode ser utilizada como técnica de caracterização, ou seja, reações modelos são escolhidas de modo a fornecerem as informações desejadas. Contudo, a realização controlada e adequação destas técnicas tendem a ser mais complexas que as anteriores. O controle dos procedimentos de avaliação catalítica e os equipamentos, usualmente montados sob medida para cada estudo, são parâmetros difíceis de serem reproduzidos. Apesar de não se relacionar diretamente com a acidez, a forma e o diâmetro dos poros também devem ser considerados para este estudo, pois exercem um papel fundamental na difusibilidade ou impedimentos estéreos envolvidos em diferentes etapas das reações. ${ }^{11,16}$

Vale lembrar que um catalisador atua modificando o mecanismo de reação, diminuindo a energia de ativação da(s) etapa(s) lenta(s). A energia de ativação relaciona-se intrinsecamente com a acidez, basicidade e a estabilidade das espécies de transição intermediárias da reação, tratados pela termodinâmica. A taxa de velocidade da reação química (ou reatividade) é função da energia de ativação e também do modelo cinético escolhido.

Enfim, a correlação entre a atividade e os valores estimados de acidez está sujeita a erros grosseiros, usualmente não computados ou omitidos na literatura.

\section{A formação de coque}

Um dos problemas mais freqüentes em sistemas que atuam com catalisadores ácidos, especialmente os que operam em elevada temperatura (ex.: craqueamento, hidrocraqueamento, pirólise, reforma, hidrodesaromatização, aromatização, desproporcionamento, alquilação, entre outros), é a formação de resíduos carbonáceos denominados comumente de coque. $\mathrm{O}$ coque formado deposita-se na superfície interna e externa dos catalisadores, impedindo o acesso aos sítios ativos e causando a desativação do material.

Por algum tempo, considerou-se que somente os catalisadores contendo sítios ácidos de Brønsted causavam a formação de coque. Hoje em dia sabe-se que, por mecanismos de reação distintos, os sítios ácidos de Lewis também catalisam a formação deste resíduo. ${ }^{17}$

O depósito de coque pode ser minimizado alterando-se as condições operacionais, como realizado nos processos na presença de vapor d'água ou sob alta pressão de gás oxidante ou hidrogênio, que favorecem a reação do coque à medida que ele é formado. Alterações das características ácido-básicas dos catalisadores também são utilizadas. A acidez do catalisador, por exemplo, pode ser controlada de modo a apresentar sítios mais fracos ou incluindo algum constituinte com características básicas, que limite a formação ou polimerização dos carbonáceos.

Dentre as zeólitas utilizadas nestes processos, a ZSM-5 destaca-se por ser relativamente resistente à formação do coque. Os pequenos poros da ZSM-5 provocam uma seletividade de forma, pois causa limitações estéricas na formação de complexos de transição de condensados aromáticos. As zeólitas de poros maiores, como as $\mathrm{X}$ ou Y, são mais susceptíveis à desativação por coqueificação. De forma geral, a geometria do poro é determinante na taxa de formação de coque nas zeólitas, enquanto a razão Si:Al e o tamanho cristalino são secundários. ${ }^{18}$

\section{CONSIDERAÇÕES FINAIS}

Os desafios impostos pela acidez da catálise em meios sólidos foram aqui ressaltados. A Tabela 1 apresenta um resumo comparativo entre a acidez em fase sólida e líquida abordadas neste artigo.

\section{AGRADECIMENTOS}

Aos Profs. A. S. Rocha, C. A. Filgueiras e P. M. Esteves por suas valiosas correções e sugestões. E. L. Moreno agradece ao suporte através da bolsa APQ1 da FAPERJ e K. Rajagopal ao suporte financeiro do MCT/FINEP/CTPETRO/PETROBRAS, através do convênio FBR 2528-06, e a bolsa de produtividade do CNPq. 
Tabela 1. Comparação entre catalisadores ácidos líquidos e sólidos

\begin{tabular}{lcc}
\hline & Ácidos líquidos & Ácidos sólidos \\
\hline Origem histórica & $\begin{array}{c}\text { Utilizados desde a antiguidade, especialmente o } \\
\text { vinagre. Em 1887, Arrhenius formalizou o } \\
\text { primeiro conceito moderno. }\end{array}$ & $\begin{array}{c}\text { Os alicerces teóricos foram construídos somente em } \\
\text { 1923, por Brønsted e Lewis. }\end{array}$ \\
\hline Quanto à teoria mais aplicada & Especialmente Brønsted. & Brønsted e Lewis. \\
Restrições ambientais & Severas, principalmente com HF e $\mathrm{H}_{2} \mathrm{SO}_{4}$. & $\begin{array}{c}\text { Comparativamente poucas, pois são mais fáceis de } \\
\text { manipular, de separar os produtos de reagentes ou de } \\
\text { reciclar o catalisador sólido. }\end{array}$ \\
\hline Síntese & Geralmente, não requer muitos esforços. & $\begin{array}{c}\text { Freqüentemente é muito elaborada, necessitando de } \\
\text { diversas etapas. }\end{array}$ \\
\hline Pesquisa & $\begin{array}{c}\text { Comparativamente bem estabelecida, } \\
\text { principalmente devido, em geral, à } \\
\text { facilidade de estudo. }\end{array}$ & $\begin{array}{c}\text { Atualmente, bastante ampla, mas em franca ex- } \\
\text { pansão, principalmente devido aos novos avanços } \\
\text { tecnológicos. }\end{array}$
\end{tabular}

Natureza química Usualmente considera-se somente a quantidade de $\mathrm{H}^{+}$
dissolvido no meio $(\mathrm{pH})$, mas em sistemas de catalise homogênea a acidez de Lewis é importante.

Medida de força e natureza

Relativamente fácil de realizar por meio de peagâmetro, papel indicador de $\mathrm{pH}$ ou indicadores.

Considera-se mais freqüentemente apenas a formação de carbocátions.

Mecanismos de reação Usualmente, fácil de correlacionar

Relação com a reatividade (especialmente em fase gasosa).

Restrito, embora bastante utilizados em processos já estabelecidos.

O coque pode se formar em meio líquido, mas

Formação de coque normalmente não constitui um problema tão crítico quanto em meio sólido.
São descritos como sítios ácidos de Lewis ou Brønsted, distribuídos pela superfície dos sólidos e em ambiente químico definido.

Diversos métodos são utilizados para estimar a força e a distribuição de sítios ácidos, dependendo do rigor e do alcance das técnicas utilizadas.

Além de carbocátions, mecanismos radicalares são comumente considerados.

Complexa. Requer que outros parâmetros sejam considerados, como cinética de reação, área específica, porosidade, homogeneidade de composição, etc.

Em tese aplicável a qualquer sistema, sendo necessário investir no estudo de condições operacionais e suportes sólidos mais adequados.

Ocorre tanto em sitos ácidos de Lewis ou Brønsted. Representam uma das principais causas de desativação de catalisadores ácidos, especialmente os que operam a elevada temperatura.

\section{REFERENCIAS}

1. Zaia, D. A. M.; Quim. Nova 2003, 26, 260.

2. Vieyra, A.; Souza-Barros, F. Em $O$ Que é a Vida: Para Entender a Biologia do Século XXI; Videira, A. A. P.; El-Hani, C. N., eds.; Dumará Relume: Rio de Janeiro, 2000, cap. 4.

3. Olah, G. A.: Goeppert, A.; Prakash, G. K. S. Em Beyond Oil and Gas: The Methanol Economy; Wiley - VCH Verlag GmbH \& Co: Weinhein, 2006, cap. 1.

4. http://www.woodrow.org/teachers/chemistry/institutes/1992/Arrhenius. html, acessada em Junho 2008.

5. Chagas, A. P.; Quim. Nova 2007, 30, 240.

6. Gama, M. da S.; Afonso, J. C.; Quim. Nova 2007, 30, 232.

7. Lowry, T. M.; J. Chem. Soc. 1927, 2562.

8. Shriver, D. F.; Atkins, P. W.; Langford, C. H.; Inorganic Chemistry, $2^{\text {nd }}$ ed., Oxford University Press: Oxford, 1994, cap. 5.

9. Hovell, I.; Coelho, R. R.; Moreno, E. L. ; Souza, A. L. de; Rajagopal, K.; Petrol. Sci. Technol. 2007, 25, 41.
10. Crépeau, G.; Montouillout, V.; Vimont, A.; Mariey, L.; Cseri, T.; Maugé, F.; J. Phys. Chem. B 2006, 110, 15172.

11. Moreno, E. L.; Tese de Doutorado, Universidade Federal do Rio de Janeiro, Brasil, 2002.

12. Abdel-Rehim, M. A.; dos Santos, A. C. B.; Camorim, V. L. L.; Faro Jr., A. C.; Appl. Catal., A 2006, 305, 211.

13. Gorte, R. J.; Catal. Lett. 1999, 62, 1.

14. Farneth, W. E.; Gorte, R. J.; Chem. Rev. 1995, 95, 615.

15. Costa, C.; Lopes, J. M.; Lemos, F.; Ribeiro, F. R.; J. Mol. Catal. A: Chem. 1999, 144, 221.

16. Gorte, R. J.; White, D.; Top. Catal. 1997, 4, 57; Parrillo, D. J.; Lee, C.; Gorte, R. J.; White, D.; Farneth, W. E.; J. Phys. Chem. 1995, 8745.

17. Câmara, L. D. T.; Cerqueira, H. S.; Aranda, D. A. G.; Rajagopal, K.; Catal. Today 2004, 98, 309.

18. Gates, B. C.; Catalytic Chemistry, Wiley: New York, 1992, cap. 5. 